\title{
Aerobic Capacity in Early Paraplegia: Implications for Rehabilitation
}

\author{
M. Ellenberg, MD, FACP, M. MacRitchie, MD, B. Franklin, PhD, \\ S. Johnson, MS, D. Wrisley, MD \\ Department of Rehabilitation Medicine and Section of Cardiovascular Diseases, \\ Sinai Hospital of Detroit, 6767 West Outer Drive, Detroit, MI 48234, USA.
}

\section{Summary}

Both strength (ability to develop tension) and endurance (aerobic capacity as measured by $\dot{V} \mathrm{O}_{2}$ max) contribute to overall functional capacity. In the rehabilitation of individuals with major neuromuscular deficits such as paraplegia, primary emphasis is generally placed on strength training to develop functional independence. However, endurance training may also be important. To clarify the influence of paraplegia on the $\dot{V} \mathrm{O}_{2}$, we studied 10 paraplegics between 2 to 12 weeks after injury to determine whether or not a deficit in arm $\dot{V} \mathrm{O}_{2}$ max was present before the inception of a conventional rehabilitation programme, and whether it persisted in three subjects after its completion. Cardiorespiratory responses to progressive multi-stage arm ergometry were measured using standard open circuit calorimetry. Ten paraplegic subjects demonstrated a low $\dot{V} \mathrm{O}_{2}$ max compared to control subjects. This deficit persisted when selected subjects $(n=3)$ were tested after completion of a conventional rehabilitation programme which emphasised strengthening exercises. Further research is needed to study the effects of complementary endurance training on the aerobic capacity as measured by $\dot{V} \mathrm{O}_{2}$ max, and to assess their value in the rehabilitation process.

Key words: Paraplegia; Cardiovascular Fitness; Aerobic Capacity; $\dot{V} \mathrm{O}_{2}$ max.

There is a well-established difference between strength (ability to develop tension) and cardiorespiratory endurance (aerobic capacity or $\dot{\mathrm{VO}}_{2}$ max). Both strength and endurance contribute to overall functional capacity. In the rehabilitation of individuals with major neuromuscular deficits such as paraplegia, primary emphasis is usually placed on strength training as the means to develop functional independence (hereafter referred to as 'conventional rehabilitation programme').

Cardiorespiratory fitness in paraplegics can be evaluated via arm ergometry 
Table I Patient characteristics

\begin{tabular}{ll}
\hline Sex & 7 Male 3 Female \\
Age & $18-42$ years \\
Etiology & 3 Motor Vehicle Accidents \\
& 2 Gunshot Wounds \\
& 2 Stabbings \\
& 1 Idiopathic Transverse Myelitis \\
& 1 Lymphoma \\
& 1 Syringomyelia \\
& T3-L4 \\
Level & 7 Complete \\
Completeness & 3 Minimal Motor Sparing \\
Average interval & 51.3 days \\
from injury to testing & \\
\hline
\end{tabular}

(Franklin, 1983; Glaser, 1978-79; Hjeltnes, 1977; Marincek, 1977-78; Rhodes, 1981) to measure various cardiorespiratory variables, particularly the maximum oxygen uptake, or $\dot{\mathrm{VO}}{ }_{2}$ max. $\dot{\mathrm{VO}}_{2}$ max, which is synonymous with the aerobic capacity of the individual, is affected by several factors including age, sex, type of exercise, anaemia, heart disease, altitude and training. The $\mathrm{VO}_{2}$ max has been measured in elite paraplegic athletes (Wicks, 1983) and paraplegics long after injury and rehabilitation (Zwiren, 1975). Few data, however, are available regarding the extent of the deficit in $\mathrm{VO}_{2}$ max in paraplegics 2-12 weeks after injury. Huang et al., (1983) evaluated the effect of three types of exercise programmes on $\mathrm{V}_{2}$ max in 'acute' paraplegic patients (mean duration since injury $=62$ days), but did not quantitate the extent of deficit beforehand.

We studied paraplegics 2 to 12 weeks after injury to determine (1) whether deficits exist in their cardiorespiratory fitness (i.e., $\mathrm{VO}_{2} \max$ ); (2) the extent of the impairment as compared to age-and sex-matched control subjects; and (3) the qualitative and quantitative degree of cardiorespiratory training and adaptation that occurs with conventional rehabilitation programmes.

\section{Materials and methods}

\section{Selection of subjects}

Ten patients with a diagnosis of paraplegia who were admitted to our rehabilitation service between August 1982 and April 1983 were studied. The patient characteristics are described in Table I. Their ages ranged from 18-42 years; 7 were male, 3 female. The etiology of paraplegia was trauma in 7 secondary to: motor vehicle accident (3), gunshot wounds (2) and knife wound (2). In addition 1 subject each had idiopathic transverse myelitis, lymphoma and syringomyelia. Despite a history of multiple associated injuries in several of the cases of trauma or the use of chemotherapy or radiation therapy, no subject had abnormal haemoglobin or other abnormal laboratory values at the time of testing. All subjects underwent progressive multi-stage arm ergometer exercise testing within 3 weeks of admission to the rehabilitation unit. Average interval between onset of paraplegia and testing was 51.3 days, but if one subject whose interval was 143 days was deleted from the calculation, the average interval was $41 \cdot 1$ days. 
Three of the 10 subjects were also tested after completion of a conventional comprehensive inpatient rehabilitation programme that emphasised strength training.

\section{Procedures}

Metabolic data, including oxygen consumption $\left(\dot{\mathrm{VO}}_{2}\right)$ (corrected to STPD), minute ventilation ( $\dot{\mathrm{VE}}$ ) (corrected to BTPS) and respiratory exchange ration $(\mathrm{R})$, equivalent to $\mathrm{CO}_{2}$ production $\left(\mathrm{V}_{\mathrm{VO}}\right)$ divided by $\dot{\mathrm{VO}}_{2}$, were obtained via the Erich Jaeger Ergo-Pneumotest/Dataspir EDV 8 system. Before each testing, the pneumotachometer was calibrated with a 1 litre syringe, and the gas analysers were calibrated with room air and a certified $\mathrm{O}_{2} / \mathrm{CO}_{2}$ concentration (Ohio Medical Products, Inc.).

Electrocardiographic (ECG) and heart rate (HR) determinations were made by Marquette Computer Assisted System for exercise. The ECG was calibrated to $1 \mathrm{mV} / 10 \mathrm{~mm}$ deflection before each test.

Tests were performed on a Schwinn model EX-2 cycle ergometer modified for arm work, as previously described (Franklin, 1983). The Schwinn ergometer is designed as rate independent within a specified range, i.e. power output in kilopond metres per minute $(\mathrm{kpm} / \mathrm{min})$, and oxygen uptake $\left(\mathrm{V}_{2}\right)$ are independent of the pedalling rate in revolutions per minute ( $\mathrm{rpm})$.

The subjects reported to the laboratory for arm ergometer testing on two separate occasions. The first session, however, involving submaximal testing, served to familiarise the subject with the test procedure and instrumentation. Protocol for the second arm test consisted of progressive continuous cranking to peak effort (volitional fatigue). The reliability of this type of ergometry had been previously documented (Bar-Or, 1975; Sawka, 1983). The initial work load was $150 \mathrm{kpm} / \mathrm{min}$, with increments of $150 \mathrm{kpm} / \mathrm{min}$ every 3 minutes. Maximum effort was determined to be that work load at which the established pedal speed (50-60 rpm) could no longer be maintained. The ECG was monitored continuously via oscilloscope, with 3 channel $\left(\mathrm{V}_{1}, \mathrm{~V}_{5}, \mathrm{aVf}\right)$ recordings made throughout the exercise test, and 12-lead ECG's obtained at the end of each stage, and during maximal exercise. Respiratory data were collected at rest, during the last 2.5 minutes of each exercise stage, and at maximal exercise.

\section{Results}

Table II shows the maximal cardiorespiratory and power output $(\mathrm{kpm} / \mathrm{min})$ values during arm ergometry for each of the 10 subjects, including the group means and standard deviations. The validity of these 'maximal' data is reflected by (1) respiratory exchange ratios $(R)$ above one in all but patient 6 ; and (2) the attainment of near-maximal age-predicted heart rates (mean maximal heart rate $=88 \%$ ). The mean maximal power output and aerobic capacity $\left(\mathrm{VO}_{2} \max \right)$ during arm ergometry were $405 \mathrm{kpm} / \mathrm{min}$ and 4.2 METs $(1 \mathrm{MET}=3.5 \mathrm{ml}$ $\mathrm{O}_{2} / \mathrm{kg} / \mathrm{min}$ ) respectively.

Table III shows the actual or measured arm aerobic capacity $\left(\dot{\mathrm{VO}}_{2} \mathrm{max}\right)$, expressed as METs, achieved by each subject, compared with the predicted 
Table II Individual cardiorespiratory and power output data at maximal exercise $(\mathrm{n}=10)$

\begin{tabular}{|c|c|c|c|c|c|c|c|c|c|c|}
\hline Pt. & & ex & $\begin{array}{l}\mathrm{HR} \\
\max \end{array}$ & $\begin{array}{c}\% \text { Age } \\
\text { pre- } \\
\text { dicted } \\
\text { HR max }{ }^{\star}\end{array}$ & $\begin{array}{c}\mathrm{VE} \\
(1 / \mathrm{min})\end{array}$ & $\begin{array}{c}\dot{\mathbf{V O}_{2}} \\
\max \\
(1 / \mathrm{min})\end{array}$ & $\begin{array}{r}\dot{\mathrm{VO}_{2}} \\
\max \\
(\mathrm{ml} / \\
\mathrm{kg} / \mathrm{min}\end{array}$ & ) & $\underset{\mathrm{min}}{\mathrm{Kpm} /}$ & ME? \\
\hline 1 & $M$ & 20 & 170 & 85 & 54.9 & $1 \cdot 14$ & $15 \cdot 6$ & 1.03 & 450 & 4.5 \\
\hline 2 & $\mathbf{M}$ & 22 & 167 & 84 & $51 \cdot 2$ & 1.43 & 14.9 & $1 \cdot 21$ & 450 & $4 \cdot 3$ \\
\hline 3 & $\mathrm{~F}$ & 39 & 164 & 91 & $28 \cdot 2$ & 0.92 & $17 \cdot 0$ & $1 \cdot 01$ & 300 & 4.9 \\
\hline 4 & M & 29 & 164 & 86 & $55 \cdot 3$ & $1 \cdot 34$ & $14 \cdot 8$ & $1 \cdot 24$ & 600 & $4 \cdot 2$ \\
\hline 5 & $\mathrm{~F}$ & 20 & 190 & 95 & $39 \cdot 3$ & 0.75 & 13.8 & $1 \cdot 32$ & 300 & 3.9 \\
\hline 6 & $\mathrm{~F}$ & 43 & 162 & 92 & $27 \cdot 6$ & 0.65 & $11 \cdot 1$ & 0.94 & 150 & $3 \cdot 2$ \\
\hline 7 & $M$ & 18 & 196 & 97 & $46 \cdot 6$ & 1.07 & $17 \cdot 0$ & $1 \cdot 31$ & 450 & 4.9 \\
\hline 8 & $M$ & 42 & 134 & 75 & $40 \cdot 1$ & $1 \cdot 22$ & 13.7 & 1.03 & 450 & 3.9 \\
\hline 9 & $\mathbf{M}$ & 23 & 158 & 80 & $37 \cdot 3$ & 0.92 & $12 \cdot 6$ & $1 \cdot 13$ & 450 & 3.6 \\
\hline 10 & $\mathrm{M}$ & 20 & 190 & 95 & $60 \cdot 0$ & $1 \cdot 14$ & $16 \cdot 3$ & 1.44 & 450 & $4 \cdot 7$ \\
\hline Mean & & $27 \cdot 0$ & $169 \cdot 5$ & 88 & $44 \cdot 1$ & 1.06 & $14 \cdot 7$ & $1 \cdot 16$ & 405 & $4 \cdot 2$ \\
\hline \pm & & \pm & \pm & \pm & \pm & \pm & \pm & \pm & \pm & \pm \\
\hline Std. Dev. & & $9 \cdot 4$ & $17 \cdot 5$ & $6 \cdot 8$ & $10 \cdot 8$ & $0 \cdot 24$ & $1 \cdot 8$ & $0 \cdot 15$ & 117 & 0.5 \\
\hline
\end{tabular}

* Maximal heart rate (HRmax) was predicted from the formula: HRmax $=220$-age. (Wilmore JH, Norton AC 1975 The heart and lungs at work: A primer of exercise physiology. Beckman Instruments Inc., Schiller Park, Illinois).

$\dagger 1 \mathrm{MET}$ (metabolic equivalent) $=3.5 \mathrm{ml} \mathrm{O} / \mathrm{kg} / \mathrm{min}$.

Table III Measured vs predicted arm aerobic capacity $\left(\mathrm{VO}_{2} \max \right)$

\begin{tabular}{|c|c|c|c|c|}
\hline Patient & $\begin{array}{c}\text { Measured } \\
\text { arm } \dot{\mathrm{VO}}_{2} \max \\
\text { METs }\end{array}$ & $\begin{array}{c}\text { Predicted } \\
\operatorname{arm}^{\star} \dot{\mathrm{VO}}_{2} \max \\
\mathrm{METs}^{2}\end{array}$ & $\%$ Normal $\dagger$ & $\begin{array}{l}\text { Interval between } \\
\text { onset of paraplegia } \\
\text { and testing (days) }\end{array}$ \\
\hline 1 & $4 \cdot 5$ & $9 \cdot 8$ & $46 \%$ & 58 \\
\hline 2 & $4 \cdot 3$ & $9 \cdot 6$ & $45 \%$ & 35 \\
\hline 3 & $4 \cdot 9$ & $5 \cdot 7$ & $86 \%$ & 143 \\
\hline 4 & $4 \cdot 2$ & $9 \cdot 0$ & $47 \%$ & 51 \\
\hline 5 & 3.9 & $7 \cdot 1$ & $55 \%$ & 39 \\
\hline 6 & $3 \cdot 2$ & $5 \cdot 4$ & $59 \%$ & 27 \\
\hline 7 & 4.9 & 9.9 & $49 \%$ & 72 \\
\hline 8 & 3.9 & $7 \cdot 8$ & $50 \%$ & 38 \\
\hline 9 & $3 \cdot 6$ & $9 \cdot 5$ & $38 \%$ & 32 \\
\hline 10 & $4 \cdot 7$ & $9 \cdot 8$ & $48 \%$ & 18 \\
\hline Mean & $4 \cdot 2$ & & $52 \%$ & $51 \cdot 3$ \\
\hline \pm & \pm & & & \\
\hline Std. Dev. & 0.5 & & & \\
\hline
\end{tabular}

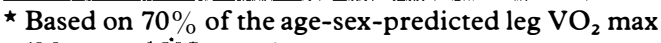

$\pm \frac{\left(\text { Measured } \mathrm{VO}_{2} \max \right)}{\left(\text { Predicted } \mathrm{VO}_{2} \max \right)} \times 100$

MET value based on Bruce's (Bruce, 1973) age-and-sex corrected normative data for leg exercise, assuming that the $\dot{\mathrm{VO}}_{2}$ max achieved with arm work is approximately $70 \%$ of that achieved with leg work (Franklin, 1985). The third column shows the percentage of predicted METs that each of our subjects attained, demonstrated a range of 38 to $86 \%$ of normal, with a mean value of $52 \%$.

Table IV shows the present data on paraplegics and the results previously obtained in our laboratory on normal men (Franklin, 1983) and women (Vander, 1984). This comparison further demonstrates the deficit in upper extremity $\dot{\mathrm{VO}}_{2} \mathrm{max}$ in our paraplegic subjects. The average $\dot{\mathrm{VO}}_{2} \max$ in METs for arm 
Table IV Comparison of maximal cardiorespiratory data on paraplegic subjects and healthy men (ref. 7)

\begin{tabular}{|c|c|c|c|c|c|c|c|c|}
\hline & Age & $\begin{array}{l}\mathrm{HR} \\
\max \end{array}$ & $\begin{array}{c}\dot{\mathrm{VE}} \\
1 / \mathrm{min}\end{array}$ & $\begin{array}{c}\dot{\mathrm{VO}_{2} \max } \\
1 / \min \end{array}$ & $\begin{array}{l}\dot{\mathrm{VO}_{2} \max } \\
\mathrm{ml} / \mathrm{kg} / \mathrm{min}\end{array}$ & $\mathbf{R}$ & $\underset{\mathrm{min}}{\mathrm{Kpm} /}$ & METs \\
\hline $\begin{array}{l}\text { Healthy men } \\
\quad(\mathrm{n}=10)\end{array}$ & $\begin{array}{c}28 \cdot 0 \\
\pm \\
2 \cdot 4\end{array}$ & $\begin{array}{c}172 \\
\pm \\
12\end{array}$ & $\begin{array}{c}84 \cdot 7 \\
\pm \\
22 \cdot 6\end{array}$ & $\begin{array}{c}2.54 \\
\pm \\
0.45\end{array}$ & $\begin{array}{c}36 \cdot 8 \\
\pm \\
6 \cdot 3\end{array}$ & $\begin{array}{c}1.06 \\
\pm \\
0.09\end{array}$ & $\begin{array}{c}675 \\
\pm \\
127\end{array}$ & $\begin{array}{c}10.5 \\
\pm \\
1.8\end{array}$ \\
\hline $\begin{array}{l}\text { Paraplegic men } \\
\quad(\mathrm{n}=7)\end{array}$ & $\begin{array}{c}24 \cdot 9 \\
\pm \\
7 \cdot 7\end{array}$ & $\begin{array}{c}168 \\
\pm \\
19\end{array}$ & $\begin{array}{c}49 \cdot 3 \\
\pm \\
7 \cdot 8\end{array}$ & $\begin{array}{c}1 \cdot 18 \\
\pm \\
0 \cdot 16\end{array}$ & $\begin{array}{c}15 \cdot 0 \\
\pm \\
1 \cdot 4\end{array}$ & $\begin{array}{c}1 \cdot 20 \\
\pm \\
0 \cdot 14\end{array}$ & $\begin{array}{c}471 \\
\pm \\
52\end{array}$ & $\begin{array}{c}4 \cdot 3 \\
\pm \\
0 \cdot 4\end{array}$ \\
\hline Difference & $3 \cdot 142$ & 3.571 & $35 \cdot 35$ & $1 \cdot 36$ & $21 \cdot 814$ & $-0 \cdot 138$ & $203 \cdot 5$ & $6 \cdot 218$ \\
\hline$\%$ Difference & $88 \cdot 8 \%$ & $97 \cdot 9 \%$ & $58 \cdot 3 \%$ & $46.5 \%$ & $40 \cdot 7 \%$ & $113 \cdot 1 \%$ & $69 \cdot 8 \%$ & $40 \cdot 8 \%$ \\
\hline
\end{tabular}

Comparison of maximal cardiorespiratory data on paraplegic subjects and healthy women (ref. 7)

\begin{tabular}{|c|c|c|c|c|c|c|c|c|}
\hline & Age & $\begin{array}{l}\mathrm{HR} \\
\max \end{array}$ & $\begin{array}{l}\dot{\mathrm{VE}} \\
1 / \mathrm{min}\end{array}$ & $\begin{array}{c}\dot{\mathrm{VO}_{2}} \max \\
1 / \min \end{array}$ & $\begin{array}{l}\dot{\mathrm{VO}} \mathrm{O}_{2} \max \\
\mathrm{ml} / \mathrm{kg} / \mathrm{min}\end{array}$ & $\mathbf{R}$ & $\begin{array}{c}\mathrm{Kpm} / \\
\min \end{array}$ & METs \\
\hline $\begin{array}{l}\text { Healthy women } \\
\quad(\mathrm{n}=10)\end{array}$ & $\begin{array}{l}29 \cdot 8 \\
\pm \\
4 \cdot 3\end{array}$ & $\begin{array}{c}169 \\
\pm \\
12\end{array}$ & $\begin{array}{c}57 \cdot 8 \\
\pm \\
15 \cdot 9\end{array}$ & $\begin{array}{c}1 \cdot 60 \\
\pm \\
0 \cdot 26\end{array}$ & $\begin{array}{c}27 \cdot 7 \\
\pm \\
5 \cdot 3\end{array}$ & $\begin{array}{l}1 \cdot 11 \\
\pm \\
0 \cdot 12\end{array}$ & $\begin{array}{c}420 \\
\pm \\
63\end{array}$ & $\begin{array}{l}7 \cdot 9 \\
\pm \\
1.5\end{array}$ \\
\hline $\begin{array}{l}\text { Paraplegic } \\
\text { women } \\
(n=7)\end{array}$ & $\begin{array}{c}34 \cdot 0 \\
\pm \\
10 \cdot 0\end{array}$ & $\begin{array}{c}172 \\
\pm \\
13\end{array}$ & $\begin{array}{l}31 \cdot 7 \\
\pm \\
5 \cdot 4\end{array}$ & $\begin{array}{c}0 \cdot 77 \\
\pm \\
0 \cdot 11\end{array}$ & $\begin{array}{c}14 \cdot 0 \\
\pm \\
1 \cdot 4\end{array}$ & $\begin{array}{c}1 \cdot 09 \\
\pm \\
0 \cdot 17\end{array}$ & $\begin{array}{l}250 \\
\pm \\
71\end{array}$ & $\begin{array}{c}4 \cdot 0 \\
\pm \\
0 \cdot 7\end{array}$ \\
\hline Difference & $-4 \cdot 2$ & -3 & $26 \cdot 1$ & $0 \cdot 83$ & $13 \cdot 7$ & 0.02 & 170 & 3.9 \\
\hline$\%$ Difference & $114 \cdot 1 \%$ & $101 \cdot 8 \%$ & $54 \cdot 8 \%$ & $48 \cdot 3 \%$ & $50 \cdot 4 \%$ & $98 \cdot 2 \%$ & $59 \cdot 5 \%$ & $50.5 \%$ \\
\hline
\end{tabular}

Table $\mathbf{V}$ Arm aerobic capacity $\left(\mathrm{V}_{2} \max \right)$ before and after a standard rehabilitation programme.

\begin{tabular}{|c|c|c|c|c|}
\hline \multirow[b]{2}{*}{ Pt. \# } & \multicolumn{2}{|c|}{ Pre-rehab. } & \multicolumn{2}{|c|}{ Post-rehab. } \\
\hline & $\begin{array}{l}\dot{\mathrm{VO}_{2} \text { max }} \\
\text { (METs) }\end{array}$ & $\%$ Normal & $\begin{array}{l}\dot{\mathrm{VO}_{2} \text { max }} \\
\text { (METs) }\end{array}$ & $\%$ Normal \\
\hline 1 & $4 \cdot 5$ & $46 \%$ & $4 \cdot 7$ & $48 \%$ \\
\hline 5 & 3.9 & $55 \%$ & $4 \cdot 1$ & $58 \%$ \\
\hline 10 & $4 \cdot 7$ & $48 \%$ & $5 \cdot 6$ & $57 \%$ \\
\hline
\end{tabular}

work was 10.5 in 10 normal able-bodied men, but only 4.3 METs in 7 similarly aged paraplegic men, or $41 \%$ of normal. Moreover, the mean $\mathrm{VO}_{2}$ max in METs for arm work was 7.9 in 10 normal able-bodied women, compared with only 4.0 METs in 3 similarly-aged paraplegic women, or $51 \%$ of normal.

Table $\mathrm{V}$ shows the effects of a conventional rehabilitation programme, emphasising strength training, on the arm aerobic capacity of 3 subjects that were retested. Although each subject showed a slight post-training improvement, none approached a normal arm $\dot{\mathrm{VO}}_{2}$ max.

\section{Discussion}

Since the first wheelchair athletic events were held at Stoke-Mandeville, UK in 1948 under the auspices of Sir Ludwig Guttmann, and with the formation of the National Wheelchair Basketball Association in the United States, 
there has been growing awareness of the benefits, both psychological and physical, of intensive exercise training for the disabled individual (Cocoran, 1980; Nilsson, 1975). Madorsky and Madorsky (1983) described the use of wheelchair racing as a tool for increasing motivation during the rehabilitation programme and facilitating re-integration into the community. The literature thus far, however, has dealt primarily with elite wheelchair athletes. Most investigators agree that considerable work remains to be done in elucidating the factors influencing cardiorespiratory capacity in the spinal cord injured population and the best means for maximising functional abilities.

Appropriate methods of testing submaximal and maximal cardiorespiratory function in the individual who is unable to undergo a standard lower extremity exercise test have been suggested (Wicks, 1977-78). Arm crank ergometry and wheelchair ergometry are the most common methods used to evaluate physiological responses to exercise in the spinal cord injured. Arm cranking is an isolated task that is easily available in the standard exercise laboratory since it requires only a modified cycle ergometer. In contrast, several authors (Glaser, 1978-79; Rhodes, 1981) suggest that a specific learned task such as wheelchair propulsion is better evaluated by wheelchair ergometry. Wicks and co-workers (Wicks, 1977-78) reported no difference in the maximal cardiorespiratory data obtained from wheelchair ergometry and arm cranking as measured by $\dot{\mathrm{VO}}_{2}$ max, heart rate, and minute ventilation. Similarly, Glaser and associates (Glaser, 1980) reported a comparable $\mathrm{VO}_{2}$ max for both exercise modes. Since both types of ergometry yielded similar $\mathrm{VO}_{2}$ max values, it was concluded that clinical exercise testing using arm cycle ergometry would probably provide a valid estimation of an individual's aerobic potential for wheelchair-type activity.

Our patients all demonstrated a significant deficit in arm aerobic capacity during the first 2 to 12 weeks following onset of paraplegia, whether compared with values based on $70 \%$ of age-sex predicted leg $\mathrm{VO}_{2} \max$ (Table III) or directly with upper extremity values measured in normal men (Franklin, 1983) and women (Vander, 1984) Table IV). We believe that the impairment in our paraplegic subjects may have been due to one or more of the following factors: (1) smaller muscle mass recruitment; (2) loss of sympathetic tone; (3) diminished maximal heart rate; and especially, (4) deconditioning after bedrest, and (5) diminished blood volume.

It is well documented that upper extremity efforts such as wheelchair propulsion elicit a higher heart rate (HR) at equivalent workloads and a lower maximum oxygen uptake $\left(\mathrm{V}_{2}\right.$ max) than work performed by the lower extremities (Marincek, 1977-78). In normal individuals, $\dot{\mathrm{VO}}_{2}$ max during arm work is approximately $70 \%$ of the $\mathrm{VO}_{2}$ max achieved during leg work, with correspondingly higher HR's relative to a given submaximal $\mathrm{VO}_{2}$ (Emes, 1981; Franklin, 1983). These responses are generally thought to be due to the smaller muscle mass involved in arm crank ergometry, as well as the inherent reduction in mechanical efficiency. The comparative cardiorespiratory values obtained for upper extremity testing in normals come from our own laboratory (Franklin, 1983; Vander, 1984). These subjects were maintained in standard positions to minimise the potential for additional muscle mass recruitment (i.e. use of leg and/or upper back muscles) that could artificially increase the arm $\mathrm{VO}_{2}$ max. Furthermore, leg musculature was inactive in our normal subjects during test- 
ing so that the 'muscle pump' effects on venous return should not have substantially augmented the results.

The possibility of loss of sympathetic input and decreased maximal heart rate in our patients was also considered. Quadriplegics and high level paraplegics have been reported to have reduced are $\mathrm{VO}_{2}$ max because of a limitation of maximal heart rate to 120 beats per minute. Apparently, this is due to a loss of sympathetic input to the heart (Wicks, 1983). However, the level of injury in most of our subjects ( 8 subjects were T6 or below) is usually not associated with such abnormalities. In fact, some of the largest deficits in $\mathrm{VO}_{2}$ max were found in patients with low lumbar level lesions. Furthermore, maximal heart rates during arm ergometry among the present paraplegic subjects were comparable to those obtained for similarly aged men and women (Table IV).

We know from the classic literature of Deitrick and associates (Deitrick, 1948) and Muller (1970) that exercise tolerance and strength take 4 to 6 weeks to recover following a period of bedrest. Factors adversely affected by prolonged bedrest include circulating blood volume, muscle mass, resting heart rate, response to the upright position (orthostatic tolerance) and various metabolic measurements, including $\mathrm{VO}_{2}$ max. All of our patients underwent several weeks of bedrest as a consequence of their injury, prior to their arm crank ergometer testing and a rehabilitation programme. This undoubtedly accounts for a large part of the deficit in their upper extremity aerobic capacity. An important feature of bedrest in the spinal cord injured individual may be the diminished blood volume. Since there is a loss of muscle tone which produces pooling in the lower extremities, there is a decrease in venous return, further lowering the circulating blood volume and adversely affecting cardiac output and aerobic capacity as compared to normals.

The 3 patients we were able to retest at the end of their conventional rehabilitation programme, although aerobically improved, failed to reach near agesex predicted values for arm $\mathrm{VO}_{2} \max$ (Table $\mathrm{V}$ ). These preliminary findings in a small number of subjects suggest that a traditional programme of upper extremity exercise and transfer activities is insufficient to favourably affect patients' cardiovascular conditioning. Since most paraplegics will lead a much more sedentary life after the onset of their disability, it would seem important for rehabilitation professionals to emphasise continued participation in endurance activities. This recommendation appears to be significant not only for psychological reasons, but to improve their future outlook for cardiovascular health. Although the 3 patients who were retested do not represent a large enough sample to draw definite conclusions, our findings highlight the need for additional studies comparing an aerobic training programme to a 'conventional rehabilitation programme'. Accordingly, Huang and co-workers found that a higher $\mathrm{VO}_{2}$ max is achieved using graded exercise as opposed to an intermittent exercise programme in paraplegic and able-bodied male subjects (Huang, 1983).

In conclusion, we have found substantial impairment in aerobic capacity using arm ergometer testing on patients during the first 2 to 12 weeks after onset of paraplegia. This is true whether related directly to values obtained from upper extremity testing on similarly aged normal subjects or from extrapolation of normative arm $\mathrm{VO}_{2}$ max from lower extremity data in the literature (Bruce, 1973). We feel the deficit may be attributed in part to the affect of bedrest, and 
decreased circulating blood volume. We have also observed that these deficits are not corrected after a traditional rehabilitation programme emphasising strength training and feel that further research should be directed at evaluating whether a normal arm $\dot{\mathrm{VO}}_{2}$ max can be achieved by complementary cardiorespiratory endurance training.

\section{References}

BAR-OR O, ZWIREN LD 1975 Maximal oxygen consumption test during arm exercise-reliability and validity. Fournal of Applied Physiology 38:424-426.

BRUCE RA 1973 Principles of exercise testing. In: NAUghton JP, Hellerstein HK (eds) Exercise Testing and Exercise Training in Coronary Heart Disease. Academic Press, New York.

Cocoran PJ, Goldman RF, HoERnER EF, et al. 1980 Sports medicine and the physiology of wheelchair marathon racing. Orthopedic Clinics of North America 11:697-716.

DeITRICK JE, WhEDON GD, SHORR E 1948 Effects of immobilization upon various metabolic and physiologic function of normal men. American fournal of Medicine 4:3-36.

EMES CG 1981 Fitness and the physically disabled. A review. Canadian fournal of Applied Sport Science 6:176-178.

FRANKLIN BA 1985 Exercise testing, training and arm ergometry. Sports Medicine 2:100-119.

FRANKLIN BA, VANDER L, WRISLEY D, et al. 1983 Aerobic requirements of arm ergometry: implications for exercise testing and training. Physical Fitness and Sports Medicine 11:81-90.

Glaser RM, Foley DM, Laubach LL, et al. 1978-79 An exercise test to evaluate fitness for wheelchair activity. Paraplegia 16:341-349.

GLASER RM, SAWKA MN, BRUNE MF, et al. 1980 Physiological responses to maximal effort wheelchair and arm crank ergometry. Fournal of Applied Physiology 48:1060-1064.

HJELTNES N 1977 Oxygen uptake and cardiac output in graded arm exercise in paraplegics with low level spinal lesions. Scandinavian fournal of Rehabilitation Medicine 9:107-113.

Huang C-H, McEachran AB, Kuhlemeier KV, et al. 1983 Prescriptive arm ergometry to optimize muscular endurance in acutely injured paraplegic patients. Archives of Physical Medicine and Rehabilitation 64:578-582.

KEMPER HCG, BINKHORST RA, VERSCHUUR R 1976 Reliability of the ergo-analyzer. Fournal of Cardiovascular Pulmonary Technology 4:27-30.

MADORSKY JG, MADORSKY A 1983 Wheelchair racing: an important modality in acute rehabilitation after paraplegia. Archives of Physical Medicine and Rehabilitation 64:186-187.

MARINCEK CRT, VALENCIC V 1977-78 Arm cycloergometry and kinetics of oxygen consumption in paraplegics. Paraplegia 15:178-185.

MULLER EA 1970 Influence of training and of inactivity on muscle strength. Archives of Physical Medicine and Rehabilitation 51:449-462.

Nilsson S, STAFF PH, PruetT EDR 1975 Physical work capacity and the effect of training of subjects with long-standing paraplegia. Scandinavian fournal of Rehabilitation Medicine 7:5156.

Rhodes EC, MCKENZIE DC, CoutTs KD, et al. 1981 A field test for the prediction of aerobic capacity in male paraplegics and quadriplegics. Canadian Applied Sports Science fournal 6:182186.

SaWka MN, Foley ME, Pimental NA, et al. 1983 Determination of maximal aerobic power during upper-body exercise. Fournal of Applied Physiology 54:113-117.

VANDER LB, FRANKLIN BA, WRISLEY D, et al. 1984 Cardiorespiratory responses to arm and leg ergometry in women. Physical Fitness and Sports Medicine 12:101-106.

WiCKS JR, LymbURNER K, DinSDALE SM, et al. 1977-78 The use of multistage exercise testing with wheelchair ergometry and arm cranking in subjects with spinal cord lesions. Paraplegia 15:252-261.

WICKS JR, OLDRIDGE NB, CAMERON BJ, et al. 1983 Arm cranking and wheelchair ergometry in elite spinal cord-injured athletes. Medicine and Science in Sports and Exercise 15: 224-231.

WILMORE JH, NoRTON AC 1975 The heart and lungs at work: A primer of exercise physiology. Beckman Instruments Inc., Schiller Park, Illinois.

ZWIREN LD, BAR-OR O 1975 Responses to exercise of paraplegics who differ in conditioning level. Medicine and Science in Sports 7:94-98. 